\title{
Hemodialysis is an Independent Predictor of Coronary In-stent Restenosis after Paclitaxel Eluting Stent Implantation
}

\author{
Ichiro Takeuchi ${ }^{1-3}$, Masahiko Moriguchi ${ }^{1}$, Ryuta Imaki ${ }^{1,2}$, Hidehira Fukaya ${ }^{1}$, \\ Hisahito Shinagawa ${ }^{1}$, Takao Shimohama ${ }^{1}$, Taiki Tojo ${ }^{1}$, Naoto Fukuda ${ }^{1}$, \\ Takayuki Inomata ${ }^{1}$, Naoyoshi Aoyama ${ }^{1}$, Kazui Soma ${ }^{2}$ and Tohru Izumi ${ }^{1}$
}

\begin{abstract}
Objective A drug eluting stent is often used for high-risk patients with complications such as diabetes mellitus (DM) and hemodialysis (HD), however the factors to predict restenosis after paclitaxel-eluting stent (PES) placement have not been reported to date.

Methods Between May 2007 and August 2009, 165 consecutive patients (231 stents) received PES in our hospital. Stent diameter and length were determined by the use of intravascular ultrasound (IVUS). All patients continued to take 2 types of anti-platelet agents (aspirin and Clopidogrel or Ticlopidine). Ninety percent of the subjects received a follow-up coronary angiogram 6 months later.

Results Underlying diseases were hypertension in $75 \%$, hyperlipidemia in $78 \%$ and DM in $60 \%(15 \%$ on insulin), and $14 \%$ of the subjects received HD. Eighty-three percent of the patients had orally taken Statin, $85 \%$ ACE/ARB and $68 \%$ had beta blockers. Mean length and diameter of PES were $21.6 \pm 7.2 \mathrm{~mm}$ and 2.9 $\pm 0.3 \mathrm{~mm}$, respectively. Target lesion revascularization (TLR) rate 6 months after PES placement was $14.6 \%$ overall. In HD patients TLR was $43 \%$, hypertension $15.0 \%$, hyperlipemia $12.4 \%$, DM with oral medication $12.5 \%$, DM with insulin $12.0 \%$, respectively. In multivariate analysis, HD was an independent risk factor for TLR ( $\mathrm{p}=0.0001$, OR: 6.61 , 95\% C.I.: 2.34-18.6).

Conclusion HD had the greatest influence on TLR after PES even though risk factors were well controlled. It is necessary to develop new PCI techniques and stents that are useful for HD patients.
\end{abstract}

Key words: drug-eluting stent, in-stent restenosis, percutaneous coronary intervention, hemodialysis

(Intern Med 49: 2379-2384, 2010)

(DOI: 10.2169/internalmedicine.49.3798)

\section{Introduction}

A conventionally-used bare metal stent (BMS) has the major problem of a high restenosis rate. It is reported that the restenosis rate with a drug eluting stent (DES) is lower than that with BMS $(1,2)$. Consequently, DES is more frequently used for high-risk patients with complications such as diabetes mellitus (DM) and hemodialysis (HD) (3). Com- pared with Western countries, percutaneous coronary intervention (PCI) is overwhelmingly more popular than coronary artery bypass graft surgery (CABG) in Japan (4). The j-Cypher registry (5) conducted in Japan shows that, among the patients to whom the Cypher sirolimus-eluting stent (SES) is used, $41 \%$ have DM and $5.5 \%$ receive HD as complications. On the other hand, in studies of Taxus- IV, V, VI, about $23 \%$ have DM (the frequency of patients on HD is not shown) (6). These results indicate that DES is more fre-

\footnotetext{
${ }^{1}$ Department of Cardio-Angiology, Kitasato University School of Medicine, Sagamihara, ${ }^{2}$ Department of Emergency \& Critical Care Medicine, Kitasato University School of Medicine, Sagamihara and ${ }^{3}$ Department of Regional Collaboration System in Perinatal and Emergency Medicine, Kitasato University School of Medicine, Sagamihara

Received for publication April 12, 2010; Accepted for publication July 22, 2010

Correspondence to Dr. Ichiro Takeuchi, itake@myad.jp
} 
Table 1. Baseline Characteristics of PES Patients

\begin{tabular}{lc}
\hline Age(years) & $66.0 \pm 9.9$ \\
Males & $141(85 \%)$ \\
Body Mass Index $\left(\mathrm{kg} / \mathrm{m}^{2}\right)$ & $24 \pm 3.6$ \\
PES patients & 165 \\
PES/patient & $1.40 / \mathrm{pt}$ \\
\multicolumn{2}{l}{ Number of coronary risk factors } \\
$\quad$ Hypertension & $127(77 \%)$ \\
Hyperlipidemia & $132(80 \%)$ \\
Diabetes mellitus & $102(62 \%)$ \\
$\quad$ insulin usage & $25(15 \%)$ \\
Smoking & \\
$\quad$ Current & $15(9 \%)$ \\
$\quad$ Ex-somoker & $96(58 \%)$ \\
$\quad$ None & $54(33 \%)$ \\
Hemodialysis & $23(14 \%)$ \\
Family history & $26(16 \%)$ \\
\hline
\end{tabular}

PES, paclitaxel-eluting stent; VLST,very late stent thrombosis CABG, coronary artery bypass grafting

quently used in patients with high risk in Japan. However, not many investigators have reported about the outcome of DES in high-risk patients. In particular, the factors to predict restenosis and target lesion revascularization (TLR) after paclitaxel-eluting stent (PES) placement have not been reported to date.

\section{Methods}

\section{Study population}

Subjects were 165 consecutive patients who received PES at our facility between May 2007 and August 2009 (the total number of PES was 231). All of the patients and their family gave written informed consent for PCI treatment before the procedure. During the study period we alternatively used PES and SES in order to avoid the influence of lesion morphology or operators' individual thoughts on the study results. PES placement was not performed for the myocardial infarction patients with ST elevation or the patients who were going to undergo surgery.

\section{$\mathrm{PCl}$ procedure}

Before the operation, $100 \mathrm{mg}$ aspirin and $75 \mathrm{mg}$ clopidogrel, or $100 \mathrm{mg}$ aspirin and $200 \mathrm{mg}$ ticlopidine were administered. After confirming there were no side effects such as hepatic impairment and thrombocytopenia, PES was placed.

The stenosis site was identified by coronary angiography (CAG), and the presence of calcification and the vascular diameter in the lesion were examined by intravascular ultrasound (IVUS). In principle, PES was placed after predilatation. IVUS was performed again after the placement to confirm the compression bonding of the stent to the vascular wall. When insufficient dilatation was observed, post dilatation using a balloon was performed as appropriate. Ninety percent of the subjects received follow-up CAG 6 months after PES placement. The other patients who did not receive CAG attended our out-patient department every two months. They had no chest symptom and no change of electrocardio-
Table 2. Clinical Events

\begin{tabular}{lc}
\hline Cardiac Death & 0 \\
Non-Cardiac death & 0 \\
SAT & $2(1.21 \%)$ \\
VLST & 0 \\
TLR & $24(14.5 \%)$ \\
CABG & 0 \\
\hline \multicolumn{2}{l}{ SAT Sub Acute Thrombosis; }
\end{tabular}

gram and ultrasonic echocardiography. There was no patient death, myocardial infarction nor stent thrombosis. As a general rule, the subjects continued to take 2 types of antiplatelet agents (aspirin, and clopidogrel or ticlopidine) till followup CAG.

CAG was multidirectionally taken after injection of nitroglycerin into the coronary artery. Coronary arteries were evaluated by quantitative coronary angiography (QCA). The minimum luminal diameter (MLD) and the length of lesion were measured, and the percent diameter stenosis (\%DS) was calculated. A lesion of not less than 50\%DS observed on follow-up CAG was defined as restenosis. PCI for TLR was performed again for the patients who had both restenosis and chest symptoms, or who was positive for myocardial ischemia on single photon emission computed tomography (SPECT).

\section{Major adverse cardiac event (MACE)}

All cause mortality, Q-wave myocardial infarction, TLR and stent thrombosis were defined as MACE.

\section{Statistical analysis}

Quantitative data were expressed as rates or mean \pm SD. Student's $t$ test was used to analyze metric variables, and chi-square test for categorical variables. Multivariate analysis was performed on parameters found to be significant in univariate analysis. $\mathrm{P}$ values of less than 0.05 were considered to be statistically significant. Statistical analysis was performed using commercially available software (SPSS for Windows, version 11.5, SPSS Inc, Chicago, IL, USA).

\section{Results}

PES placement was performed in 165 consecutive patients at our facility between May 2007 and August 2009, and the total number of PES was 231. The average number of PES per patient was 1.4 .

\section{Baseline characteristics}

Average age of patients was 66 years, and $85 \%$ were males. Approximately $80 \%$ of the patients had hypertension and hyperlipidemia as underlying diseases. In addition, $62 \%$ had DM and $15 \%$ used insulin. Twenty-three patients (14\%) received HD (Table 1).

\section{Clinical events}

As shown in Table 2, neither cardiac death nor noncardiac death was observed within 6 months after PES 
Table 3. Comparison of Patient Characteristics between TLR(-) and TLR(+)

\begin{tabular}{lccc}
\hline & $\begin{array}{c}\text { TLR(-) } \\
(\mathrm{n}=141)\end{array}$ & $\begin{array}{c}\text { TLR(+) } \\
(\mathrm{n}=24)\end{array}$ & p value \\
\hline Age(years) & $66.6 \pm 10.3$ & $68.4 \pm 7.2$ & \\
Males & $118(84 \%)$ & $23(96 \%)$ & 0.206 \\
Height(cm) & $160.9 \pm 9.1$ & $161.8 \pm 6.5$ & 0.674 \\
Weight(kg) & $63.4 \pm 12.4$ & $59.7 \pm 9.9$ & 0.180 \\
BMI $\left(\mathrm{kg} / \mathrm{m}^{2}\right)$ & $24.3 \pm 3.7$ & $22.7 \pm 2.7$ & 0.040 \\
Waist(cm) & $85.4 \pm 10.8$ & $81.2 \pm 8.6$ & 0.076 \\
\hline Number of coronary risk factors & $105(92 \%)$ & & \\
$\quad$ Hypertension & $112(79 \%)$ & $15(63 \%)$ & 0.800 \\
Hyperlipidemia & $86(61 \%)$ & $16(67 \%)$ & 0.188 \\
Diabetes mellitus & $22(16 \%)$ & $3(13 \%)$ & 0.824 \\
$\quad$ insulin usage & $13(9 \%)$ & $2(8 \%)$ & 0.695 \\
Smoking & $82(58 \%)$ & $14(58 \%)$ & \\
$\quad$ Current & $86(33 \%)$ & $8(33 \%)$ & 0.990 \\
$\quad$ Ex-smoker & $13(9 \%)$ & $10(42 \%)$ & 0.0001 \\
$\quad$ None & $21(15 \%)$ & $5(21 \%)$ & 0.460 \\
$\quad$ Hemodialysis & & & \\
\hline
\end{tabular}

TLR, Target lesion revascularization; BMI, body mass index;

Table 4. Oral Medication and Laboratory Data at Follow-up CAG

\begin{tabular}{lccc}
\hline & $\begin{array}{c}\text { TLR(-) } \\
(\mathrm{n}=141)\end{array}$ & $\begin{array}{c}\text { TLR(+) } \\
(\mathrm{n}=24)\end{array}$ & p value \\
\hline Aspirin & $141(100 \%)$ & $24(100 \%)$ & \\
Clopidogrel & $66(47 \%)$ & $12(50 \%)$ & 0.772 \\
Ticlopidine & $68(48 \%)$ & $11(46 \%)$ & 0.828 \\
Warfarin & $21(15 \%)$ & $2(8 \%)$ & 0.391 \\
Statin & $120(85 \%)$ & $18(75 \%)$ & 0.216 \\
ACE inhibitor/ARB & $123(87 \%)$ & $17(71 \%)$ & 0.038 \\
Beta blocker & $97(69 \%)$ & $15(63 \%)$ & 0.542 \\
Calcium blocker & $70(50 \%)$ & $15(63 \%)$ & 0.244 \\
\hline Total-cholsterol(mg/dL) & $163 \pm 32$ & $148 \pm 26$ & 0.033 \\
TG(mg/dL) & $154 \pm 110$ & $136 \pm 86$ & 0.455 \\
HDL(mg/dL) & $53 \pm 17$ & $52 \pm 15$ & 0.813 \\
LDL(mg/dL) & $92 \pm 28$ & $81 \pm 20$ & 0.068 \\
HbA1c(\%) & $6.15 \pm 1.13$ & $6.17 \pm 0.87$ & 0.938 \\
Creatinine(mg/dL) & $1.39 \pm 1.56$ & $1.65 \pm 2.39$ & 0.492 \\
\hline
\end{tabular}

CAG, coronary angiography; ACE,Angiotensin Converting Enzyme Inhibitor;

ARB, angiotensin receptor blocker;

TG, triglyceride; HDL, high density lipoprotein; LDL, low density lipoprotein

placement. Two patients developed sub-acute thrombosis: One patient had discontinued anti-platelet agents by himself. In the other patient, ticlopidine was changed to cilostazol due to an allergy to ticlopidine. The catheter was performed urgently in both patients at the time of SAT onset. In both patients, new stent placement was not performed, and blood flow was improved only by thrombus suction and temporary IABP support. Both patients recovered and were discharged. These 2 patients continued to take antiplatelet agents after discharge, and no restesnosis was observed on 6-month follow-up CAG. Therefore, SAT observed in these 2 patients was thought to be caused by discontinuation of antiplatelet agents.

CABG was performed for no patient within 6 months after PES placement. Twenty-four patients $(14.5 \%)$ had re-PCI for TLR 6 months after the placement.

\section{Comparison between patients with and without TLR}

Table 3 shows the comparison between the patients with $(\mathrm{n}=24)$ and without $(\mathrm{n}=141)$ TLR (TLR(+) and TLR(-) groups, respectively). The mean age of TLR(+) group (68 years) was similar to that of TLR(-) group (66 years). There was no significant difference in the gender distribution. No difference was observed in height or abdominal girth, but the TLR(+) group had a significantly lower body mass index (BMI) than the TLR(-) group $(\mathrm{p}=0.04)$. Concerning complications, there was no difference in the frequency of diabetes mellitus, or the frequency of insulin usage. TLR(+) group received hemodialysis significantly more than TLR(-) group $(\mathrm{p}=0.0001)$.

Aspirin was orally taken by all patients, and also either clopidogrel or ticlopidine was orally taken at the time of 6month follow-up. Statin was orally taken by $85 \%$ of the patients even in TLR(-) group. Beta blocker was orally administered to not less than $60 \%$ of both TLR(+) and TLR(-) groups. Angiotensin-converting enzyme (ACE) inhibitor/angiotensin receptor blockers (ARB) was orally taken significantly less by TLR(+) group than TLR(-) group ( $\mathrm{p}=0.038)$ (Table 4).

And also, Table 4 shows blood test results at the time of 6-month follow-up CAG. Low-density lipoprotein (LDL) cholesterol was controlled well by statins in both $\operatorname{TLR}(+)$ and TLR(-) groups. The total cholesterol level tended to be lower in $\operatorname{TLR}(+)$ group $(\mathrm{p}=0.033)$. Table 5 shows the com- 
Table 5. Comparison of Lesion Characteristics between TLR(-) and $\operatorname{TLR}(+)$

\begin{tabular}{lccc}
\hline & $\begin{array}{c}\text { TLR(-) } \\
(n=141)\end{array}$ & $\begin{array}{c}\text { TLR(+) } \\
(n=24)\end{array}$ & p value \\
\hline Clinical diagnosis & $76(54 \%)$ & $14(58 \%)$ & \\
eAP & $12(9 \%)$ & $1(4 \%)$ & 0.754 \\
uAP(non-STEMI) & $53(38 \%)$ & $9(38 \%)$ & \\
OMI & & $16(67 \%)$ & \\
Lesion characteristics & $103(73 \%)$ & $3(13 \%)$ & \\
de novo & $7(5 \%)$ & $4(17 \%)$ & 0.255 \\
CTO & $14(9.9 \%)$ & $1(4 \%)$ & \\
Cypher ISR & $7(5 \%)$ & $1(25 \%)$ & 0.216 \\
BMS ISR & $21(15 \%)$ & & \\
Bifurcation & &
\end{tabular}

eAP,effort angina pectoris; uAP, unstable angina pectoris

STEMI,ST-segment elevation myocardial infarction; OMI, old myocardial infarction

CTO,Chronic Total Occlusion; ISR, in stent restenosis; BMS,bare metal stent

Table 6. PCI Procedure

\begin{tabular}{lccc}
\hline & $\begin{array}{c}\text { TLR(-) } \\
(\mathrm{n}=141)\end{array}$ & $\begin{array}{c}\text { TLR(+) } \\
(\mathrm{n}=24)\end{array}$ & p value \\
\hline Stent length(mm) & $21 \pm 7$ & $20 \pm 7$ & 0.503 \\
Stent size(mm) & $2.9 \pm 0.3$ & $2.8 \pm 0.2$ & 0.248 \\
Stent/Lesion ratio & $1.3 \pm 0.4$ & $1.2 \pm 0.4$ & 0.345 \\
Post dilatation & $120(85 \%)$ & $20(83 \%)$ & 0.765 \\
Final balloon size $(\mathrm{mm})$ & $3.24 \pm 0.44$ & $3.04 \pm 0.34$ & 0.672 \\
\hline
\end{tabular}

Table 7. Comparison of QCA and IVUS Findings between TLR(-) and TLR(+)

\begin{tabular}{cccc}
\hline & $\begin{array}{c}\text { TLR(-) } \\
(\mathbf{n}=141)\end{array}$ & $\begin{array}{c}\text { TLR(+) } \\
(\mathbf{n}=24)\end{array}$ & p value \\
\hline Pre & & & \\
MLD & $1.04 \pm 0.73$ & $0.81 \pm 0.56$ & 0.540 \\
\%DS & $74.3 \pm 33.0$ & $68.2 \pm 24$ & 0.280 \\
Post & & & \\
MLD & $2.51 \pm 0.36$ & $2.62 \pm 0.60$ & 0.110 \\
\%DS & $12.5 \pm 9.26$ & $8.64 \pm 11.5$ & 0.167 \\
MSA & $5.4 \pm 1.9$ & $5.1 \pm 1.7$ & 0.092 \\
\hline
\end{tabular}

QCA, quantitative coronary angiography; IVUS, intravascular ultrasound imaging

MLD, minimal lumen diameter; DS, diameter stenosis; MSA, minimal stent area

Table 8. Multivariate Logistic Regression Analysis for Prediction of TLR

\begin{tabular}{lccc}
\hline & OR & $95 \% \mathrm{CI}$ & p value \\
\hline Hemodialysis & 6.608 & $2.34-18.64$ & 0.0001 \\
Total-cholesterol(mg/dL) & 0.98 & $0.962-0.999$ & 0.038 \\
ACEinhibitor/ARB & 0.252 & $0.082-0.776$ & 0.016 \\
BMI $\left(\mathrm{kg} / \mathrm{m}^{2}\right)$ & & & 0.330 \\
\hline
\end{tabular}

parison of lesion morphology and other comparisons between TLR(+) and TLR(-) groups. There was no difference in the frequency of angina or old myocardial infarction (OMI). Furthermore, no difference in the incidence of de novo lesion, chronic total occlusion (CTO), or restenosis in the stent was observed between the two groups.

Concerning PCI procedures (Table 6), there was no difference in mean stent length or diameter. No difference was observed in the presence of post-dilatation or balloon size between TLR(+) and TLR(-) groups. In addition, there was no difference in MLD observed by QCA or MSA by IVUS between the two groups (Table 7).

\section{Prediction of TLR}

Among the investigated factors, HD, total cholesterol, treatment with ACE inhibitors/ARB and BMI showed significant differences between TLR(+) and TLR(-) groups. Multivariate logistic regression analysis was performed for these factors. Consequently, hemodialysis was the most significant factor to predict TLR for PES ( $p=0.0001$, OR: 6.608, 95\% C.I.: 2.34-18.64) (Table 8).

\section{Discussion}

\section{DES in high-risk patients}

Since DES is reported to demonstrate a markedly reduced restenosis rate compared to BMS, it is coming to be used more for high-risk patients $(1,2)$.

Some studies have reported the results of SES in high- 
risk patients (7-11) but few reports discuss the outcomes when using PES in high-risk patients. In our study, the factors to influence TLR for PES in patients with very high risks (i.e., 77\% had hypertension, 80\% hyperlipidemia and $62 \%$ DM; $15 \%$ used insulin; and 14\% received HD) were investigated. Approximately $80 \%$ of the patients with hyperlipidemia were administered statin, and it was controlled very well [LDL-cholesterol: $92 \pm 28 \mathrm{mg} / \mathrm{dL}$ in TLR(+) group, and $81 \pm 20 \mathrm{mg} / \mathrm{dL}$ in TLR(-) group]. Mean blood pressure was $124 \mathrm{mmHg}$ (data not shown) even in TLR(+) group. Seventy percent of all patients received ACE inhibitors/ARB and $60 \%$ beta blockers, and blood pressure was wellcontrolled in both TLR(+) and TLR(-) groups.

Our study subjects included numerous high-risk patients with complications, but they were well treated and favorably controlled. However, the rate of TLR was high. Therefore, we investigated which factor had the greatest influence on TLR. Consequently, the most important factor to predict TLR was the presence of HD, but not DM or usage of insulin. Stent restenosis in HD patients is still a major issue (12). Our study results indicated that they still had a higher restenosis rate even when using PES.

In Japan, new DESs (e.g., ZES; zotarolimus eluting stent, and EES; everolimus eluting stent) have become available. However, how to select the appropriate DES in Japanese patients has not been clarified yet. We should evaluate new DESs in HD patients, whose restenosis rate could not be lowered by PES, in order to confirm whether they are effective even for HD patients.

\section{Hemodialysis patients}

According to $\mathrm{NIH}$, the most frequent cause of death in HD patients is cardiovascular-related diseases (45\%) (13). The HD patients have better long-term survival after CABG than PCI (14). But recent reports from the BMS era showed comparable long-term survival after percutaneous and surgical coronary revascularization procedures in renal transplant recipients (15), the invasiveness of surgical methods contributes to an increased rate of in-hospital death and postoperative stroke (16).

It is reported that, when using BMS, the rate of TLR is higher in HD patients than in non-HD patients (17). Causes of restenosis in hemodialysis patients include chronic vascular inflammation, poor dilation (18) due to calcification (19-21), and complications of not only cardiac dysfunction but other organ dysfunctions. However, in our study, there was no difference in post-MSA measured by IVUS, or post-MLD analyzed by QCA between TLR(+) and TLR(-) groups. Therefore, technical factors such as poor dilation of the vessels were not the causes of the high TLR rate in HD patients. The incidence of restenosis in HD patients is high and stent restenosis is still a major issue (12). The reason for this might be that the mechanism of restenosis in HD patients is highly related to vessel shrinkage and neointimal hyperplasia (22).

In this study, multivariate analysis showed that the factors to predict TLR in high-risk patients were BMI, the presence of hemodialysis, low cholesterol level, and administration of ACE inhibitors/ARB. HD had the greatest influence on TLR after PES. It is necessary to develop new PCI techniques and stents that are useful for HD patients in the near future.

\section{Conclusion}

The incidence of restenosis was high when using PES in HD patients. We should investigate stent placement techniques, oral medicines, and outcomes of new DESs in HD patients in order to confirm whether they were effective even for HD patients.

\section{Study limitations}

Our study limitation was that this was a retrospective investigation, and not a randomized comparative study. Consequently, it was realized that even PES had limitations in HD patients. If stents and techniques that are useful for HD patients are developed, we should perform prospective studies on such patients in the future.

In addition, the number of subjects in this study (165 consecutive patients) was not sufficiently large. We wish to undertake a study with a larger number of subjects.

\section{References}

1. Morice MC, Serruys PW, Sousa JE, et al; RAVEL Study Group. A randomized comparison of a sirolimus-eluting stent with a standard stent for coronary revascularization. $N$ Engl J Med 346: 1773-1780, 2002.

2. Moses JW, Leon MB, Popma JJ, et al; SIRIUS Investigators. Sirolimus-eluting stents versus standard stents in patients with stenosis in a native coronary artery. N Engl J Med 349: 13151323, 2003.

3. Lasala JM, Cox DA, Morris DL, et al. Two-year results of paclitaxel-eluting stents in patients with medically treated diabetes mellitus from the TAXUS ARRIVE program. Am J Cardiol 103: 1663-1671, 2009.

4. Kamiya M, Takayama M, Takano H, et al. Clinical outcome and quality of life of octogenarian patients following percutaneous coronary intervention or surgical coronary revascularization. Circ J 71: 847-854, 2007.

5. Kimura T, Morimoto T, Nakagawa Y, et al; j-Cypher Registry Investigators. Antiplatelet therapy and stent thrombosis after sirolimus-eluting stent implantation. Circulation 119: 987-995, 2009.

6. Ellis SG, Colombo A, Grube E, et al. Incidence, timing, and correlates of stent thrombosis with the polymeric paclitaxel drugeluting stent: a TAXUS II, IV, V, and VI meta-analysis of 3,445 patients followed for up to 3 years. J Am Coll Cardiol 49: 10431051, 2007.

7. Ishio N, Kobayashi Y, Takebayashi H, et al. Impact of drugeluting stents on clinical and angiographic outcomes in dialysis patients. Circ J 71: 1525-1529, 2007.

8. Aoyama T, Ishii H, Toriyama T, et al. Sirolimus-eluting stents vs bare metal stents for coronary intervention in Japanese patients with renal failure on hemodialysis. Circ J 72: 56-60, 2008.

9. Okada T, Hayashi Y, Toyofuku M, et al. One-year clinical outcomes of dialysis patients after implantation with sirolimus-eluting coronary stents. Circ J 72: 1430-1435, 2008.

10. Hassani SE, Chu WW, Wolfram RM, et al. Clinical outcomes after percutaneous coronary intervention with drug-eluting stents in di- 
alysis patients. J Invasive Cardiol 18: 273-277, 2006.

11. Halkin A, Selzer F, Marroquin O, Laskey W, Detre K, Cohen H. Clinical outcomes following percutaneous coronary intervention with drug-eluting vs bare-metal stents in dialysis patients. J Invasive Cardiol 18: 577-583, 2006.

12. El-Menyar AA, Al Suwaidi J, Holmes DR Jr. Use of drug-eluting stents in patients with coronary artery disease and renal insufficiency. Mayo Clin Proc 85: 165-171, 2010.

13. National Institutes of Health, National Institute of Diabetes and Digestive and Kidney Disease. Renal data system: USRDS 2002 annual data report. Bethesda: NIH, 2002.

14. Herzog CA, Ma JZ, Collins AJ. Comparative survival of dialysis patients in the United States after coronary angioplasty, coronary artery stenting, and coronary artery bypass surgery and impact of diabetes. Circulation 106: 2207-2211, 2002.

15. Herzog CA, Ma JZ, Collins AJ. Long-term outcome of renal transplant recipients in the United States after coronary revascularization procedures. Circulation 109: 2866-2871, 2004.

16. Liu JY, Birkmeyer NJ, Sanders JH, et al. Risks of morbidity and mortality in dialysis patients undergoing coronary artery bypass surgery: Northern New England Cardiovascular Disease Study
Group. Circulation 102: 2973-2977, 2000.

17. Moussa I, Di Mario C, Moses J, et al. Coronary stenting after rotational atherectomy in calcified and complex lesions: Angiographic and clinical follow-up results. Circulation 96: 128-136, 1997.

18. Mintz GS, Weissman NJ. Intravascular ultrasound in the drugeluting stent era. J Am Coll Cardiol 48: 421-429, 2006.

19. Schwarz U, Buzello M, Ritz E, et al. Morphology of coronary atherosclerotic lesions in patients with end-stage renal failure. Nephrol Dial Transplant 15: 218-223, 2000.

20. Bocksch W, Fateh-Moghadam S, Mueller E, Huehns S, Waigand J, Dietz R. Percutaneous coronary intervention in patients with end-stage renal disease. Kidney Blood Press Res 28: 275-279, 2005.

21. Fujii K, Mintz GS, Kobayashi Y, et al. Contribution of stent underexpansion to recurrence after sirolimus-eluting stent implantation for in-stent restenosis. Circulation 109: 1085-1088, 2004.

22. Nakazawa G, Tanabe K, Aoki J, et al. Impact of renal insufficiency on clinical and angiographic outcomes following percutaneous coronary intervention with sirolimus-eluting stents. Catheter Cardiovasc Interv 69: 808-814, 2007.

(C) 2010 The Japanese Society of Internal Medicine http://www.naika.or.jp/imindex.html 